\title{
ASPECTOS MORFO-ANATÔMICOS DE SEMENTES DE Podocarpus lambertii Klotz. E Podocarpus sellowii Klotz. - PODOCARPACEAE ${ }^{1}$
}

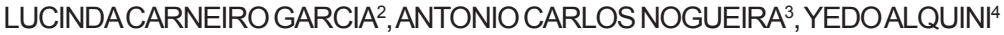

\begin{abstract}
RESUMO - Estudos relacionados à morfo-anatomia de frutos e sementes de espécies florestais são relevantes para a compreensão de vários fenômenos ligados ao comportamento dessas espécies. O presente trabalho é uma contribuição ao estudo das características morfológicas e anatômicas de sementes de Podocarpus lambertii Klotz. e Podocarpus sellowii Klotz.. Para as observações do desenvolvimento dos estróbilos, foram efetuadas visitas quinzenais às áreas de coleta, a partir do início da formação dos estróbilos até a maturação das sementes. A cada visita, foram retiradas amostras para análises de microscopia estereoscópica e fotônica. O estróbilo feminino de P. lambertii e $P$. sellowii é constituído pela semente e epimácio, presos a um delgado pedúnculo. As sementes de $P$. lambertii e $P$. sellowii são globosas, possuem tegumento com estrutura espessa, constituído de três camadas celulares. O endosperma é abundante e de consistência gelatinosa; o embrião é do tipo linear e cotiledonar.
\end{abstract}

Termos para indexação: pinheiro-bravo, estróbilos, morfologia, anatomia.

\section{MORPHOLOGICALANATOMICALASPECTS OF Podocarpus lambertii Klotz. AND Podocarpus sellowii Klotz. (PODOCARPACEAE) SEEDS}

\begin{abstract}
Seed and fruit development studies are essential for comprehension of forest species performance. The aim of these studies was to follow the complete development and dispersal of Podocarpus lambertii Klotz. and Podocarpus sellowii Klotz. seeds. Fortnightly collections in the selected areas were made from the start of bract formation to seed ripeness. Materials collected were analyzed under photonic and stereoscopic microscopy. Female strobilus consist of seed and epimatium, fixed on a thin peduncle. The seeds are globe-shaped, with tegment consiting of three cellular layers. The endosperm of the seeds is abundant and of gelatine consistency. The embryo of both species is linear and cotyledonous.
\end{abstract}

Index terms: pinheiro-bravo, strobilus, morphology, anatomy.

\section{INTRODUÇÃO}

Pesquisas sobre a morfo-anatomia de sementes de espécies florestais são relevantes para a compreensão de vários fenômenos ligados ao comportamento dessas espécies. Estudos concernentes à morfologia e anatomia são fundamentais no conhecimento dos processos fisiológicos das plantas, nas investigações sobre a taxonomia das espécies

\footnotetext{
${ }^{1}$ Submetido em 06/12/2005. Aceito para publicação em 24/07/2006. Parte da tese de doutorado da primeira autora aprentada à Universidade Federal do Paraná (UFPR);

${ }^{2}$ Eng. Agrônomo, D.Sc., Embrapa Amazônia Ocidental, Caixa Postal 319,
}

e, também, na formulação de projetos de ecologia, dentre outros.

O conhecimento em anatomia vegetal, especificamente sobre as estruturas reprodutivas de algumas espécies arbóreas oriundas das regiões sul e sudeste do Brasil, ainda é escasso. Quando se trata de espécies pertencentes à ordem Gymnospermae nativas, essas informações praticamente tornam-se inexistentes (Kuniyoshi, 1983; Inoue et al., 1984;

\footnotetext{
CEP: 69011-970, Manaus - AM, lucinda@cpaa.embrapa.br;

${ }^{3}$ Eng. Florestal, D.Sc., Universidade Federal do Paraná (UFPR);
}

${ }^{4}$ Biólogo, D.Sc., Universidade Federal do Paraná (UFPR). 
Ragagnin et al., 1994).

Em decorrência desses fatos, torna-se imprescindível intensificar os estudos referentes à morfo-anatomia das sementes dessas espécies arbóreas nativas, levando-se em consideração que conhecimentos básicos são indispensáveis para o planejamento e execução de programas de plantios florestais para fins econômicos e ecológicos.

Podocarpus lambertii Klotz. e Podocarpus sellowii Klotz. são Gymnospermae, Ordem Coniferales e Família Podocarpaceae (Duarte, 1973; Joly, 1991). São espécies que ocorrem naturalmente na Floresta Ombrófila Mista (Floresta com Araucaria) e Floresta Ombrófila Densa (Floresta Atlântica), respectivamente, e apesar de se tratar de espécies com distribuição natural nas regiões sul e sudeste do Brasil, com reconhecido potencial econômico e ecológico, são pouco estudadas, no que diz respeito aos aspectos morfo-anatômicos de suas sementes.

O presente trabalho é uma contribuição ao estudo das características morfológicas e anatômicas de sementes de Podocarpus lambertii Klotz. e Podocarpus sellowii Klotz.

\section{MATERIAL E MÉTODOS}

As sementes de Podocarpus lambertii e P. sellowii usadas neste trabalho, foram provenientes de matrizes de áreas da região metropolitana de Curitiba, Paraná. Foram selecionadas dez matrizes de cada espécie, baseando-se nos seguintes parâmetros: tronco bem formado, sem tortuosidade; copa grande e densa, de modo a ter boa exposição ao sol e produção abundante de sementes. A distância mínima observada entre as matrizes foi de $30 \mathrm{~m}$. A coleta foi efetuada nas árvores, com auxílio de um podão.

O estudo contemplou desde o lançamento dos estróbilos femininos até o completo desenvolvimento e dispersão das sementes.

As matrizes selecionadas foram acompanhadas quinzenalmente, a partir do estágio de formação da estrutura reprodutiva, onde se efetuou a coleta de amostras dos estróbilos das espécies, em diferentes fases de desenvolvimento. Os estudos morfológicos e anatômicos foram realizados em material fresco e material fixado em FAA - 70 (Johansen, 1940), por 48 horas e armazenadas em álcool $70 \%$.

Parte das amostras foi analisada sob microscopia estereoscópica (MES) e parte por microscopia fotônica (MF). As de microscopia fotônica foram submetidas à desidratação, em série alcoólico-etílica e emblocadas em glicol metacrilato
(GMA), de acordo com a técnica de Feder e O'Brien (1968).

Foram efetuadas secções longitudinais e/ou transversais, de $7 \mu \mathrm{m}$ de espessura, obtidas em micrótomo rotatório, e a coloração foi efetuada com azul de toluidina $0,05 \%$ (O’Brien et al., 1965). A montagem das lâminas permanentes foi realizada com resina sintética. Os registros fotográficos foram efetuados em microscópio fotônico Zeiss, marca Axiolab e microscópio estereoscópico, marca Stemi-2000-C, acoplados com máquina fotográfica. As escalas foram projetadas sob as mesmas condições ópticas.

As características físicas e morfológicas das sementes foram descritas a partir de amostras de 100 unidades, oriundas de indivíduos diferentes, de ambas as espécies.

\section{RESULTADOS E DISCUSSÃO}

P. lambertii e $P$. sellowii são espécies dióicas, com estróbilos femininos solitários, axilares, localizados na região basal da folha e são sustentados por um pedúnculo de 5 a $15 \mathrm{~mm}$ (Figuras 1A e 1B).

$\mathrm{Na}$ descrição da morfologia externa do estróbilo das espécies, é importante citar que este é constituído pela semente propriamente dita e por um receptáculo carnoso, aderido a esta. Spjut (1994) e Tomlinson (1994) relatam que dentre as Gymnospermae, a família Podocarpaceae se destaca por possuir um receptáculo dilatado aderido à semente, conhecido como epimácio.

$\mathrm{Na}$ fase inicial de desenvolvimento da semente, observouse o epimácio com bráctea aderida (Figuras 2A e 2B). Em estágio mais desenvolvido da semente, verificou-se que a bráctea se desprende do epimácio (Figuras 3A e 3B). A mudança de coloração verde do epimácio, quando no início de formação e fase de desenvolvimento, para a cor roxa, é um importante indicativo no processo de maturação da semente, nas duas espécies estudadas (Figuras 4A e 4B).

A semente de $P$. lambertii e $P$. sellowii possui tegumento com estrutura espessa, porém, de consistência tênue. Este é constituído de três camadas celulares que, morfologicamente, podem ser descritas como: uma externa coriácea, lignificada, e com canais resiníferos, denominada exotesta; uma intermediária e delgada, aderida à primeira, chamada mesotesta, e uma terceira, também delgada, denominada endotesta, envolve o endosperma primário (Figuras 5A e 5B).

Segundo Beltrati (1990), nas Gymnospermae, o tegumento é histologicamente diferenciado em três zonas: uma camada externa carnosa; uma camada mediana "pétrea" ou esclerenquimática e uma camada interna carnosa, sendo que 
Fotos: Garcia, L.C.
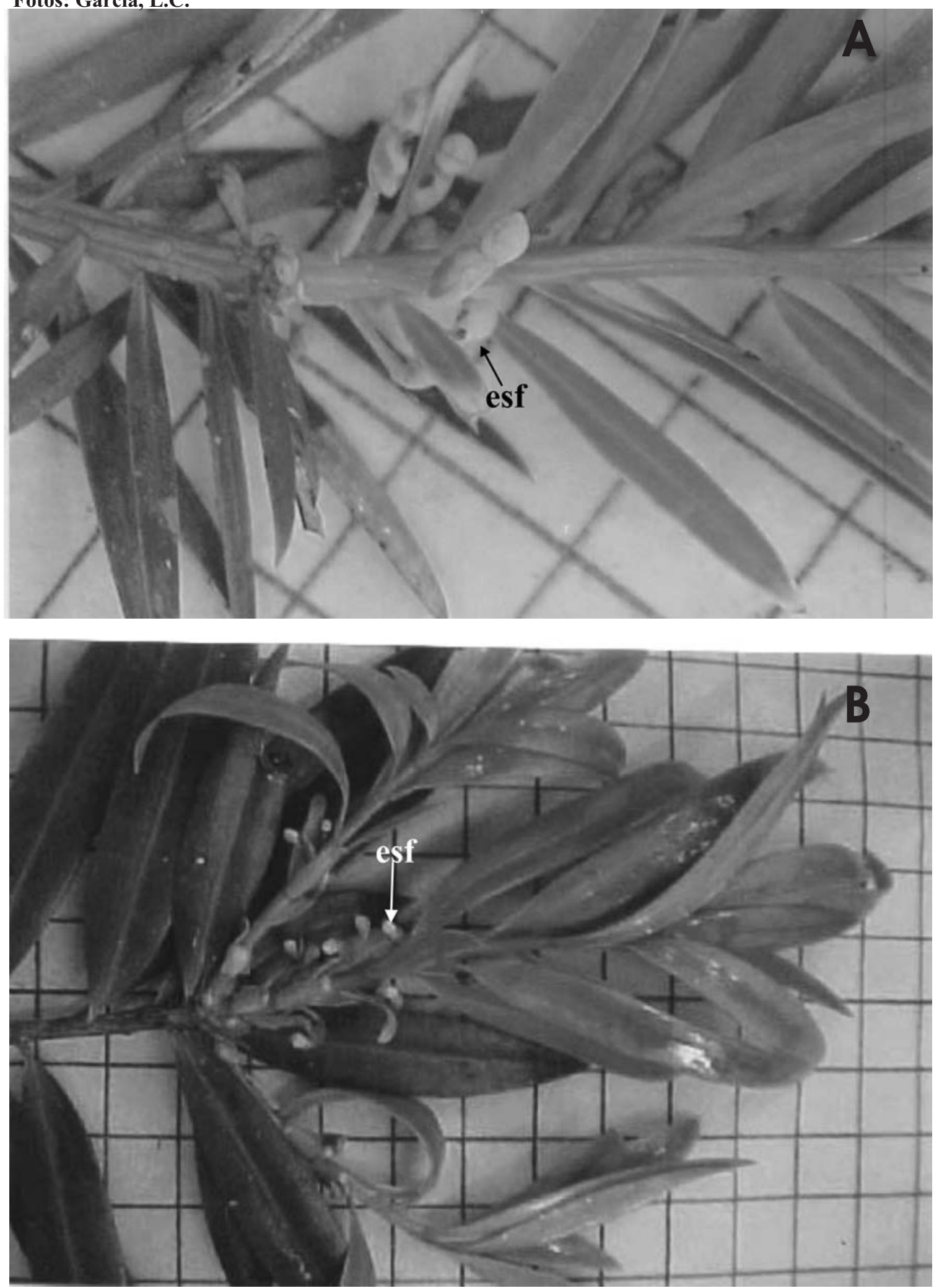

FIGURA 1. Estróbilos femininos de Podocarpus lambertii Klotz (A) e Podocarpus sellowii Klotz (B). 
Fotos: Garcia, L.C.

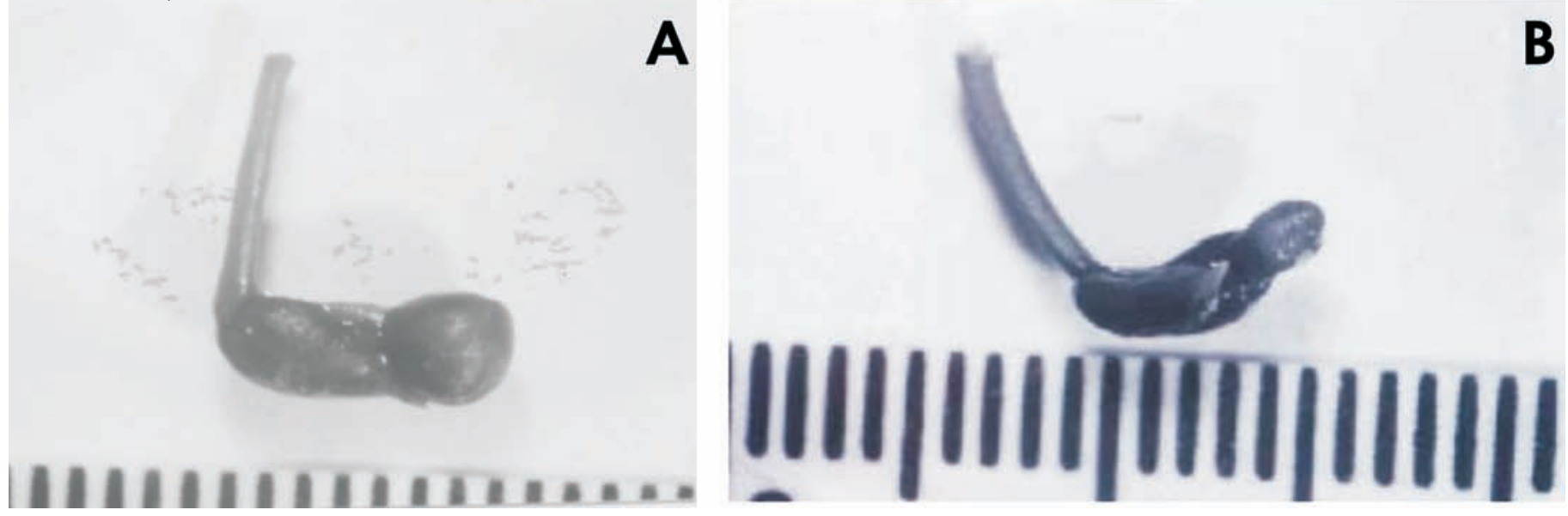

FIGURA 2. Estróbilo de Podocarpus lambertii Klotz. (A) e P. sellowii Klotz. (B) em fase jovem.

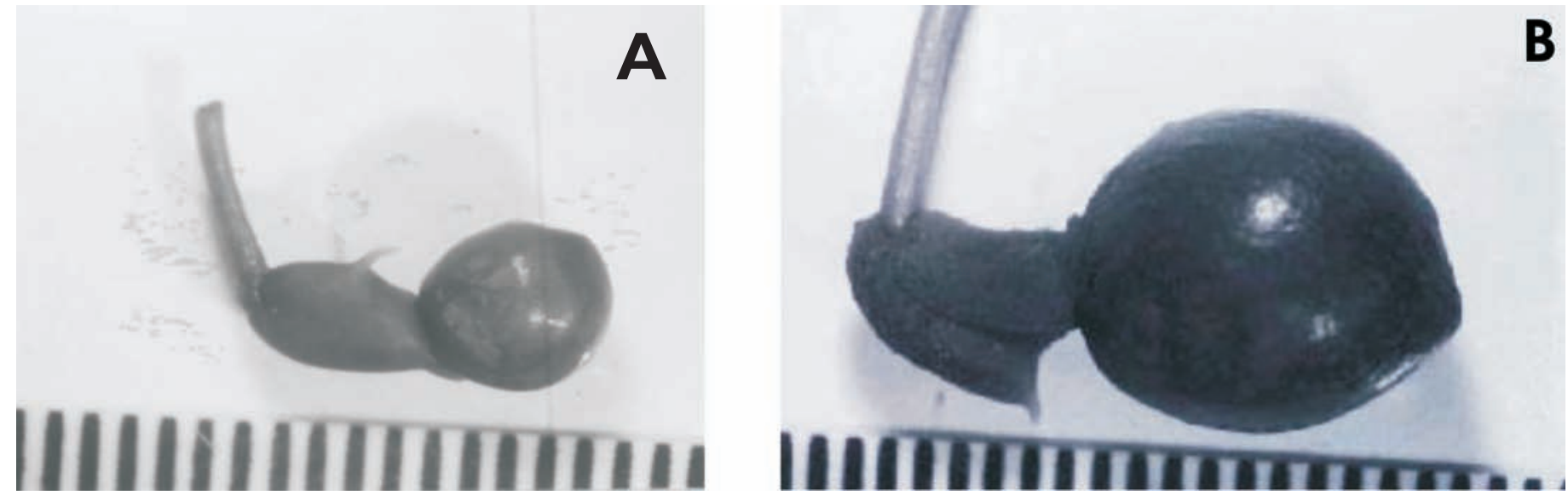

FIGURA 3. Estróbilo de Podocarpus lambertii Klotz. (A) e P. sellowii Klotz. (B) em fase avançada de desenvolvimento.
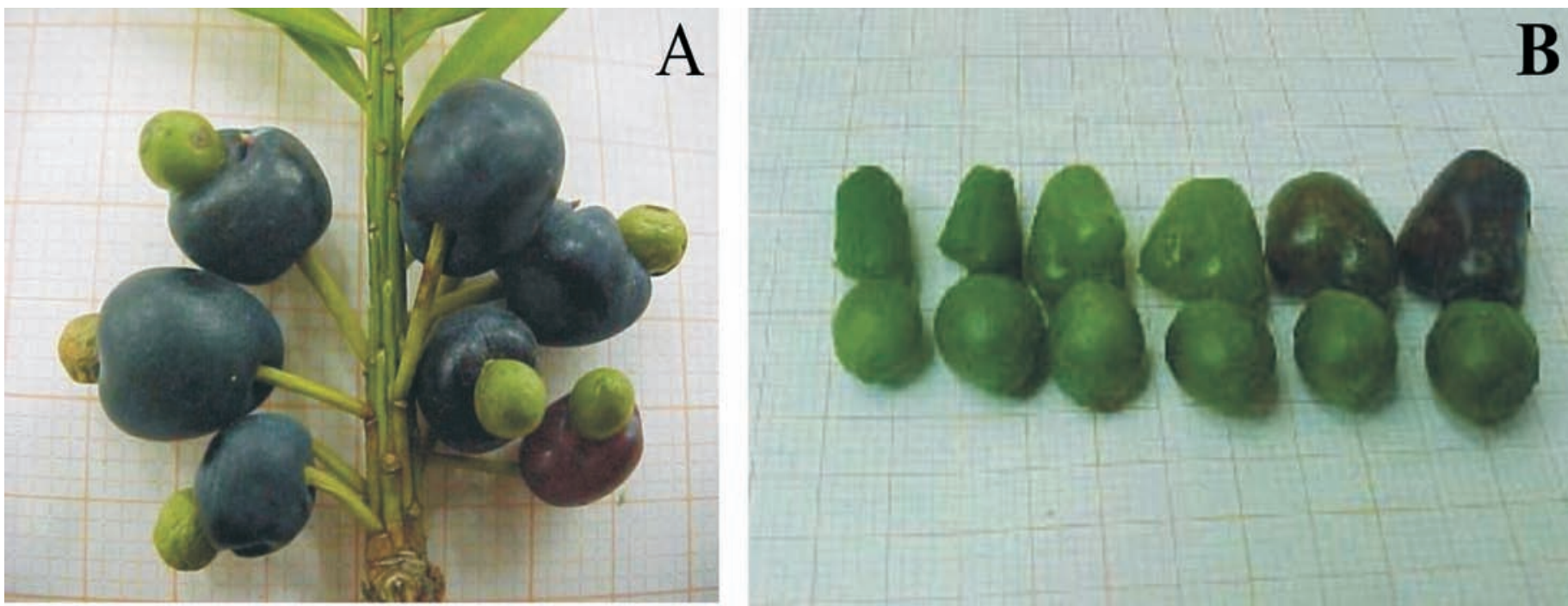

FIGURA 4. Estróbilos maduros de Podocarpus lambertii Klotz. (A) e P. sellowii Klotz. (B). 
o grau de desenvolvimento de cada uma das camadas, durante a ontogenia da semente, varia nos diferentes grupos dessas espécies. Em muitas coníferas, a camada externa carnosa é rudimentar, enquanto que em outras, essa camada é grossa e pode ser muito pigmentada na semente madura.

Verificou-se que o endosperma da semente de P. lambertii e $P$. sellowii se caracteriza como uma massa homogênea, abundante, de cor branca e consistência gelatinosa (Figuras $5 \mathrm{~A}$ e $5 \mathrm{~B})$.

Observou-se também que, o embrião de $P$. lambertii e $P$. sellowii é do tipo linear e cotiledonar e se encontra anatomicamente desenvolvido, na fase final de maturação da semente, com ápice arredondado, dois cotilédones e eixo hipocótilo-radícula bem definidos (Figuras 6A e 6B).
Os dados das análises físicas e morfológicas das sementes estudadas, encontram-se nas Tabelas 1 e 2.

As sementes de $P$. lambertii são pequenas, globosas, com ápice e base mucronados, levemente estriadas, de consistência coriácea e coloração variando entre verde pálido, bege e castanho-amarelada, quando maduras. As sementes de $P$. sellowii também são globosas, levemente estriadas e coriáceas, porém, são maiores do que as de $P$. lambertii, o que pode ser constatado pelo resultado da massa de 1.000 sementes e número de sementes por quilograma, bem como, pelos dados de dimensões das sementes das duas espécies (Tabelas 1 e 2).

Pelos resultados obtidos, verificou-se que as sementes trabalhadas possuem grau de umidade muito diferentes. As
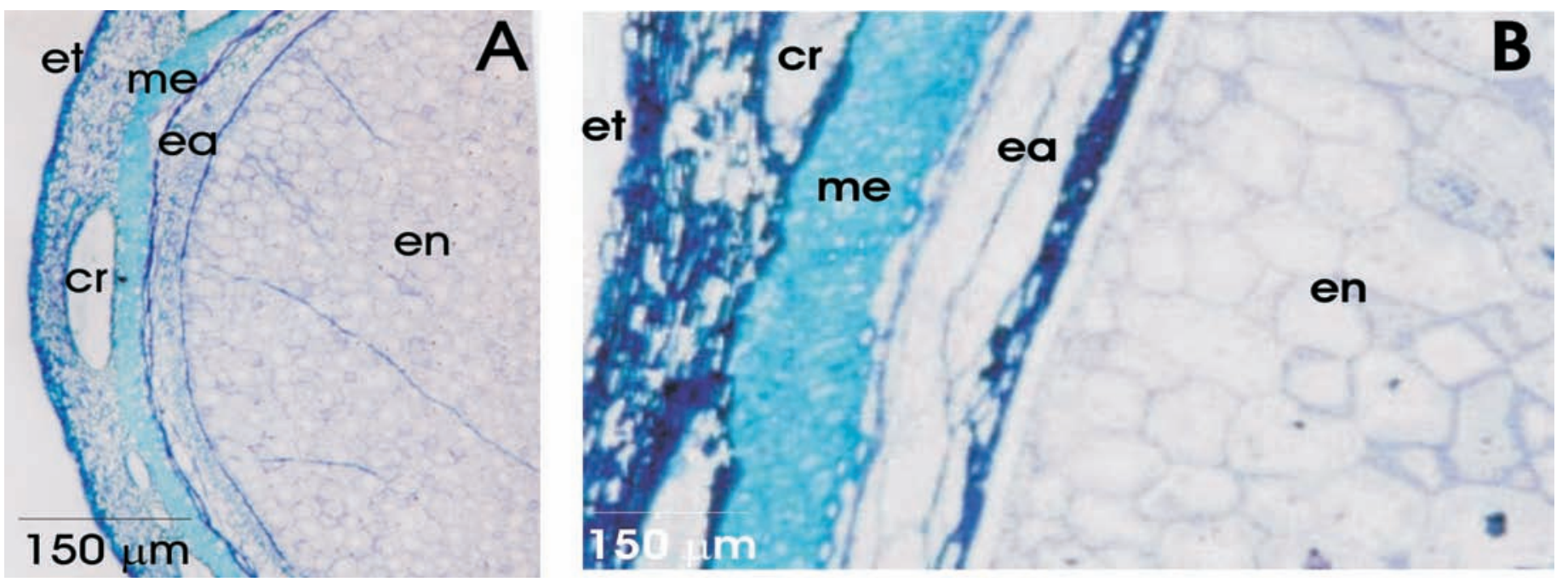

FIGURA 5. Vista geral de tegumento e endosperma de Podocarpus lambertii Klotz. (A) e P. sellowii Klotz. (B). Legenda: et exotesta; me-mesotesta; ea-endotesta; cr-canais resiníferos; en-endosperma.
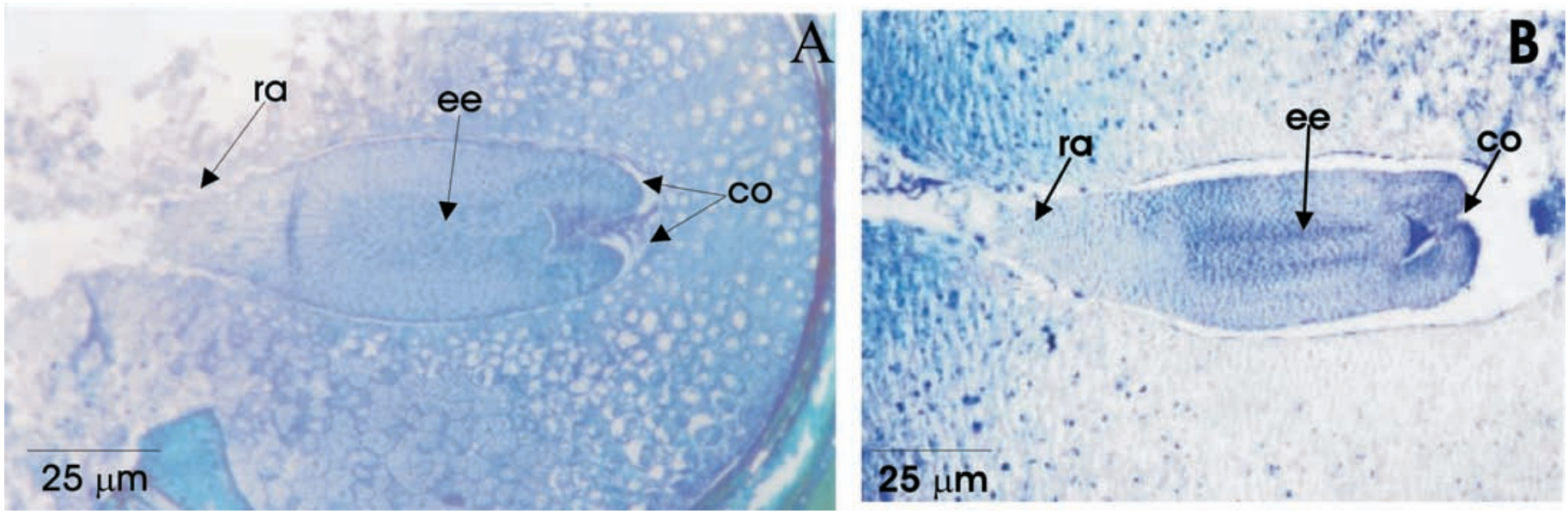

FIGURA 6. Embrião de Podocarpus lambertii Klotz. (A) e P. sellowii Klotz. (B). Legenda: ra - radícula; ee - eixo embrionário; co cotilédones. 
TABELA 1. Análises físicas e dimensões de sementes de Podocarpus lambertii Klotz.

\begin{tabular}{lccccc}
\hline Dimensões* $(\mathrm{mm})$ & Máxima & Mínima & Média & Desvio Padrão & Coeficiente de Variação (\%) \\
\hline Comprimento & 5,53 & 3,97 & 4,74 & 0,28 & 5,99 \\
Diâmetro & 4,79 & 3,33 & 3,87 & 0,22 & 5,71 \\
\hline \multicolumn{1}{c}{ Pureza (\%) } & Massa 1000 sementes $(\mathrm{g})$ & \multicolumn{2}{c}{$\mathrm{N}^{\circ}$ de sementes.kg } & Umidade inicial (\%) \\
\hline \multicolumn{2}{c}{37,52} & \multicolumn{2}{c}{26.649} & 28,7 \\
\hline
\end{tabular}

*Médias de 100 sementes.

TABELA 2 . Análises físicas e dimensões de sementes de Podocarpus sellowii Klotz.

\begin{tabular}{lccccc}
\hline Dimensões* $(\mathrm{mm})$ & Máxima & Mínima & Média & Desvio Padrão & Coeficiente de Variação $(\%)$ \\
\hline Comprimento & 10,63 & 7,10 & 9,01 & 0,64 & 7,14 \\
Diâmetro & 8,76 & 6,40 & 7,49 & 0,51 & 6,83 \\
\hline \multicolumn{1}{c}{ Pureza (\%) } & Massa 1.000 sementes $(\mathrm{g})$ & $\mathrm{N}^{\circ}$ de sementes. $\mathrm{kg}^{-1}$ & Umidade inicial $(\%)$ \\
\hline \multicolumn{2}{c}{270,6} & \multicolumn{2}{c}{3.695} & 45,5 \\
\hline
\end{tabular}

*Médias de 100 sementes.

sementes de $P$. lambertii apresentaram umidade inicial de $28,7 \%$ e as de $P$. sellowii $45,5 \%$ (Tabelas 1 e 2). Tal fato, provavelmente, pode-se explicar pelas condições ecológicas características dos habitats naturais das duas espécies, tendo em vista que a Floresta Atlântica é caracterizada por possuir alto grau de umidade em seu ambiente, quando comparada à Floresta com Araucaria.

\section{CONCLUSÕES}

As sementes de Podocarpus lambertii e P. sellowii possuem tegumento com camadas celulares de estrutura espessa, porém, de consistência tênua; endosperma abundante e de consistência gelatinosa; embrião linear e cotiledonar.

As sementes estudadas apresentam características morfo-anatômicas semelhantes, porém, divergem muito com relação ao tamanho e ao teor de água inicial.

\section{AGRADECIMENTOS}

Ao Biólogo Nilson Belém Filho, técnico do Laboratório de Botânica Estrutural/UFPR, pela cuidadosa e eficiente preparação das lâminas.

\section{REFERÊNCIAS}

BELTRATI, C.M. Morfologia e anatomia de sementes. São Paulo:
Departamento de Botânica, Campus de Rio Claro, Instituto de Biociências, 1990. 100p.

DUARTE, A.P. Tentativa para explicar a ocorrência de duas espécies de Podocarpus no Brasil. Brasil Florestal, Rio de Janeiro, v.4, n.13, p.53-66, 1973

FEDER, N.; O'BRIEN, T.P. Plant microtechnique: some principles and new methods. American Journal of Botany, New York, v.5, n.1, p.123-142, 1968.

INOUE, M.T.; RODERJAN, C.V.; KUNIYOSHI, Y.S. Projeto madeira do Paraná. Curitiba: Fundação de Pesquisas Florestais do Paraná, 1984. 260p.

JOHANSEN, D.A. Plant microtechnique. New York: Mc GrawHill Book, 1940. 523p.

JOLY, A.B. Botânica: introdução à taxonomia vegetal. 10.ed. São Paulo: Editora Nacional, 1991. 777p.

KUNIYOSHI, Y.S. Morfologia da semente e da germinação de 25 espécies arbóreas de uma floresta com Araucaria. 1983. 233f. Dissertação (Mestrado em Silvicultura) - Faculdade de Ciências Agrárias, Universidade Federal do Paraná, Curitiba, 1983.

O'BRIEN, T.P.; FEDER, N.; McCULLY, M.E. Polychromatic staining of plant cell walls by toluidine blue. O Protoplasma, New York, v.59, n.1, p.368-373, 1965 .

RAGAGNIN, L.I.M.; COSTA, E.C.; HOPPE, J.M. Maturação fisiológica de sementes de Podocarpus lambertii Klotzsch. Ciência Florestal, Santa Maria, v.4, n.1, p.23-41, 1994.

SPJUT, R.W. A systematic treatment of fruit types. New York: The New York Botanical Garden, 1994. 181p.

TOMLINSON, P.B. Functional morphology of saccate pollen in conifers with special reference to Podocarpaceae. International Journal of Plants Science, Chicago, v.155, n.6, p.699-715, 1994. 